\title{
Landslide in fractured and stratified rocks: A case from Aizawl, Mizoram, India
}

\author{
PK Singh, Ratan Das and TN Singh \\ Indian Institute of Technology Bombay, \\ Mumbai, India \\ psingh.geo@gmail.com
}

\author{
KK Singh \\ Geological Survey of India \\ Hyderabad, India \\ karfuekunal@gmail.com
}

\begin{abstract}
Stratified rock cut slopes for e.g. shale-sandstonesiltstone layers are a common occurrence in some part of the Himalayas. These rocks are highly jointed and bears low strength to sustain significant engineering load. A similar geological condition exists in the north eastern Himalayas (Aizawl, Mizoram) where such rocks have been exposed along cut slopes. The area receives heavy rainfall during the monsoonal months and the presence of clay make these rocks highly susceptible to intense weathering. Further, the presence of widely spaced orthogonal joints along with persistent bedding parallel joints allow water to percolate deeper into the formation. Accumulation of water with time in the pore spaces of rocks and in the interface between the strata leads to opening of the joints and considerable reduction of shear strength. Despite of incompetency of these rocks, large number of transportation lines and settlements are being built to meet the demand of increasing population in India. Unscientific design and inadequate use of geological and geotechnical information during construction allow these rocks to deteriorate and degrade in strength before the engineering life of the structure eventually leading to slope failure and mass destruction. Therefore, the present study mainly deals with the influence of long term weathering on the strength degradation of the exposed rocks by a series of experimental observations followed by numerical simulation of cut slope using distinct element method. The purpose is to gauge into the health of the slope and the processes which leads to slope failure under normal gravity and hydro-mechanical loading conditions. The result of this analysis is very promising which discusses several important issues like effective loading direction, maximum allowed load on the crest of the slope, zones of maximum displacement and maximum flow rate observed along the slope face, mode and depth of failure plane. Understanding these challenges will assist the planners to design appropriate support systems for long term safety and sustainability of the structures and avoid future slope failure.
\end{abstract} failure

Keywords-landslide, fractured and stratified rock; slope

\section{INTRODUCTION}

Stratified rock successions such as shale, sandstone, siltstone is very common in the Himalayan geology. These rocks possess characteristic lamination/bedding planes which is acquired during the sedimentation process. As a result of this, stratified rocks are formed having large continuity parallel to bedding plane. Tang et al [1] suggests that during the process of stratification, the dip and mechanical properties of bedding plane bear significant effect on the strength and stability. It has been reported earlier that the process of planar failure becomes highly dominant and results in most rockslides in stratified rocks [2], [3]. Compositionally, rocks like shale, sandstone, siltstone are often rich in clay minerals. Presence of clay in varying amounts is a major trigger in strength degradation when exposed to atmospheric agents. In addition, the presence of orthogonal joint sets is always a common occurrence in stratified rocks, a parameter responsible for intense weathering at subsurface levels. These inherent characteristic of stratified rocks are responsible for most of the slope failure along cut slopes.

Many researchers have observed delayed failure in slopes cut in over-consolidated fissured clays. The reason for such behaviour is lower pore pressure value observed after the excavation of slope than the ultimate equilibrium values [4]. Vaughan and Walbancke [5] suggest that reduction in strength is often accompanied during equilibration of pore pressure and failure is delayed by the swelling rate. Reduction in strength due to breaking of inter-particle bonds as a result of weathering is another cause of delayed failure [6]. High rate of weathering facilitates rapid change in the initial rock material properties. Therefore, stratified material rich in clays show various degrees of disintegration characteristics such as blocks, plates, flakes and slabs [7]. Another important factor is the porosity and permeability characteristics of these material which varies significantly. This property of shalesandstone-siltstone strata makes the interface very weak leading to considerable reduction of shear strength. Therefore, slope stability analysis in stratified rocks becomes very difficult especially in presence of water.

In India, stratified rocks are a very common occurrence in the Lower Himalayas. Construction and widening of preexisting roads without proper utilization of engineering practices expose the rock mass to various weathering agents. NE Himalayas receive heavy precipitation during monsoonal months which makes the condition even worse. Therefore, the frequency of slope failure in fractured and stratified rocks are generally encountered in cut slopes in India. To study the influence of planar anisotropy on progressive failure of stratified rocks, a number of uniaxial compression tests were performed on silty shale samples with different orientation of bedding plane. Numerical simulation was later done to 
understand the mechanics of progressive failure by incorporating fluid flow through fractures.

\section{STUDY AREA AND GEOLOGY}

A stratified rock slope failed in the Chaltlang village of Aizawl district, Mizoram, India on May 11, 2013 uprooting several houses killing around more than 25 people. The slope failure was triggered due incessant rains in the last three days which led to closure of road for several days. The exposed cut slope constitutes shale-sandstone-siltstone succession over and around which a number of houses are built. Surma group of rocks are the major lithounits in Mizoram mainly represented by Bokabil and Bhuban Formations. While Lower and Upper Bhuban Formations are mainly arenaceous composed of sandstones, Middle Bhuban Formation is mostly argillaceous characterized by thinly bedded shale, siltstone and sandstone. Bokabil Formation, having gradational contact overlies Upper Bhuban Formation, is mostly argillaceous and occurs on the flanks of the ridge or in the cores of synclines. The formations are folded into tight symmetrical synclines and anticlines along N-S axis. The strike of the bedding planes varies from NNE-SSW with a dip of around 40-50 either towards east or west. Faults can be observed in the entire area mainly of transverse, longitudinal and oblique types displacing the folding sequence (Fig. 1).

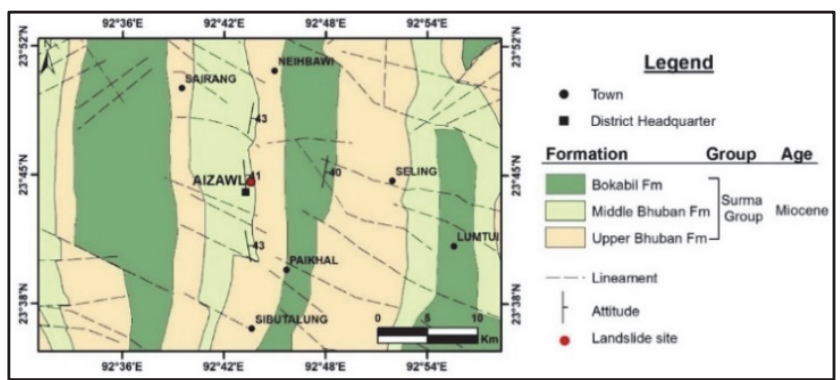

Fig. 1. Lithology map of the study area showing different formations with structural features (red dot shows location of failed site)

\section{Methodology}

\section{A. Field observation}

Aizawl district in Mizoram is densely populated on a ridge with rugged topography. The area is characterized by steep slopes with moderate to high rate of weathering as a result of heavy rainfall. The product of intense weathering is reflected in a thick pile of unconsolidated material deposited over the slope. The maximum observed thickness reaches a depth of about 1-1.5 m. Field survey was conducted post slope failure for detailed engineering geological investigation of rock joint and rock mass characterization. Samples in the form of rectangular block of around $15 \times 10 \times 12 \mathrm{~cm}^{3}$ were collected from the freshly exposed slope surface as well as the dislodged material (failed blocks) for examining the geomechanical parameters. Three joint sets are present viz., Bedding plane, $\mathrm{J} 1\left(\mathrm{~N} 5^{\circ} \mathrm{W} / 45^{\circ} \mathrm{E}\right) ; \mathrm{J} 2\left(\mathrm{~N} 85^{\circ} \mathrm{E} / 90^{\circ}\right)$ and $\mathrm{J} 3$ $\left(\mathrm{N} 10^{\circ} \mathrm{E} / 70^{\circ} \mathrm{SE}\right)$. The general trend of the slope face is $\mathrm{N} 10^{\circ} \mathrm{W}$, dipping towards $55^{\circ} \mathrm{NE}$. The failed slope is around $50 \mathrm{~m}$ in height with curvo linear failure surface. The joint surface seems very smooth. The bedding parallel joints are very thinly laminated and daylights on the slope face, which makes this condition a typical site for planar failure. Fig. 2

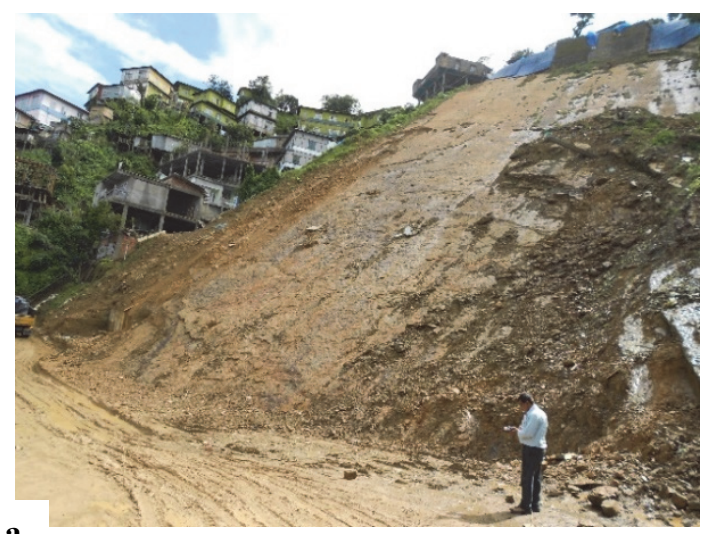

$\mathbf{a}$

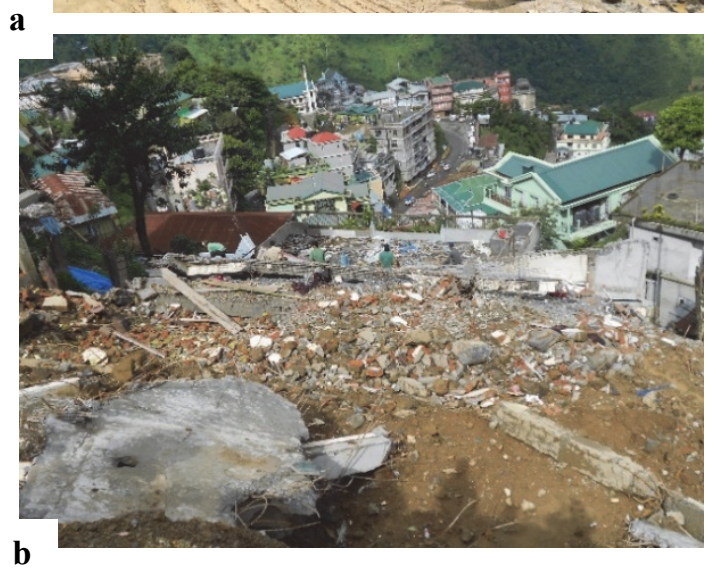

Fig. ... ... tographs of the failed site in Chaltlang, Mizoram showing a) failed cut slope section b) damaged houses and transportation lines

shows failed cut slope section along with damages settlement and transportation lines.

\section{B. Geomechanical properties}

Identification of geomechanical properties of laminated rocks is very difficult task because of the problems in collecting intact samples as well preparing finished cores. However, with utmost precaution intact core were obtained for different inclination of bedding plane at $0^{\circ}, 30^{\circ}, 45^{\circ}$ and $90^{\circ}$. Intact compressive strength was obtained for the four cases. Other than this, elastic modulus, Poisson's ratio, tensile strength, slake durability index, density and porosity was also obtained to understand the behaviour of the rock in response to different loading conditions and. The purpose of slake durability test was solely to investigate the effect of water or a typical cycle of wetting and drying on the exposed rocks along cut slope. The average result of all the tests is summarized in Table I and is further discussed in the later sections. Some of these material parameters were also used as an input in the numerical simulation.

TABLE I GeOMEChaniCAL Properties OF The SAMPLES Determined IN LABORATORY

\begin{tabular}{|l|l|l|l|l|l|l|l|}
\hline Material & $\begin{array}{l}\text { Density } \\
\left(\mathbf{g} / \mathbf{c m}^{\mathbf{3}}\right)\end{array}$ & $\begin{array}{l}\text { UCS } \\
(\mathbf{M P a})\end{array}$ & $\begin{array}{l}\text { BTS } \\
(\mathbf{M P a})\end{array}$ & $\begin{array}{l}\mathbf{C} \\
(\mathbf{M P a})\end{array}$ & $\begin{array}{l}\text { Phi } \\
\left({ }^{\circ}\right)\end{array}$ & $\begin{array}{l}\text { E } \\
(\mathbf{M P a})\end{array}$ & $\mathbf{v}$ \\
\hline Fresh & 2300 & $32.6 / 16.7$ & $3.5 / 1.2$ & 8 & 34 & 11000 & 0.29 \\
\hline Failed & 2000 & 15.4 & - & - & - & - & - \\
\hline
\end{tabular}


Under uniaxial loading fractures are free to grow without any resistance. If any planar anisotropy (lamination, schistosity, cleavage) is present in the rock, the failure behaviour is mostly controlled by them. The basic theory of fracture mechanics suggests that with increase in confining stress, the load bearing capacity of the material increases. Donath [8] performed a series of test on such anisotropic rocks and suggested that at low confining pressures planar anisotropy has significant effect both on breaking strength as well as on the angle of shear fracture. This simply means that at a greater depth within the surface of the earth, the effect of anisotropy on shear fracture will be negligible due to high confining stresses and fractures will tend to form nearly parallel to the loading direction.

The second aspect is the long term weathering of stratified rocks and its susceptibility to breakdown upon contact with water. Durability of a material is its ability to resist abrasion and is particularly important for shales and other weak rocks [7]. All rocks behave differently under the repeated cycles of drying and wetting. Shale has the potential to absorb excessive volume of water leading to degradation of shear strength with time. Swelling and shrinkage is a common phenomenon in shaly rocks. Clay rich rocks are susceptible to slow volume change and works independent of loading however, swelling is not observed in rocks with intact UCS exceeding 40 [9]. Swelling causes breakage of structural elements whereas, shrinkage expedites the formation of fractures along pre-existing microcracks. This invites two interdependent process running at the same time. First, it degrades the shear strength of the material and at the same time increases the hydraulic conductivity. For this purpose, slake durability test was conducted on the silty shale samples for two cycles.

\section{Numerical simulation}

Numerical simulation is a tool that can help to visualize the complex processes taking place in real situation and also predict future conditions. The Distinct Element Method is a numerical technique where the computational domain consists of discrete solid elements that interact through compliant contacts. This method is mostly used for fractured rock systems, granular media and has been used extensively in rock engineering [10], [11]. In Discrete Element Method, the independent particles can be either rigid or deformable, and can have circular or polygonal shape [12]. A great advantage of Discrete Element Method compared to continuum based model is that meshes are built by individual elements and there is no need for re-meshing as the simulation progresses. The most widely used discrete element code for slope stability study is UDEC (Universal Distinct Element Code; Itasca Consulting Group, 2000). Cundall and Hart [13] defined that DEM belongs to the family of discrete element methods which permits finite rotations and displacements of discrete bodies also including detachment and automatically identifies new contacts between bodies during calculations. Fluid flow in UDEC makes use of domain structure assumed to be filled with fluid at uniform pressure at constant pressure. In each domain, uniform fluid pressure exists in absence of gravity whereas, the pressure varies linearly following hydraulic gradient in problems with gravity. Cubic law for parallel plate model [14] can be assumed for estimating the flow rate in case of planar fractures with edge to edge contact (equation (1)).

$$
q=-k_{j} a^{3} \frac{\Delta p}{l}
$$

Where $q$ is the flow rate, $\mathrm{m}^{3} / \mathrm{s} ; k_{j}$ is joint permeability factor, $\mathrm{Pa}^{-1} \mathrm{~s}^{-1}(1 / 12 \mu) ; \mu$ is the dynamic viscosity of the fluid, Pa.s; $a$ is the contact hydraulic aperture, $\mathrm{m}$; and $l$ is the length assigned to the contact between the domains, $\mathrm{m}$.

The height of the modelled slope is $50 \mathrm{~m}$ from the mean sea level of $1100 \mathrm{~m}$. The present slope angle is $45^{\circ}$ with planar to curvilinear surface while the assumed topography represents a slope angle of around $50^{\circ}$. The upper slope material constitutes of silty shale with alternate layering of siltstone, sandstone and shale (Fig. 3). The bottom boundary of the slope was fixed while water pressure equivalent to $40 \mathrm{~m}$ head was applied from the right boundary.

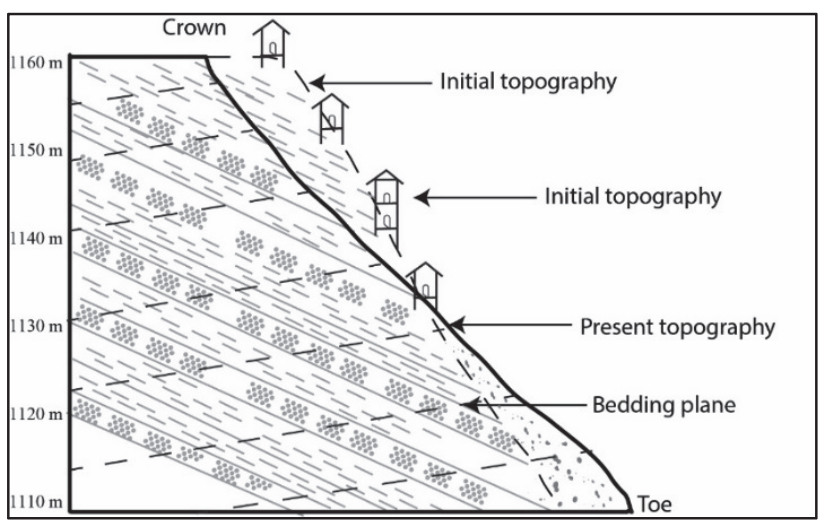

Fig. 3. Cut slope section showing present and assumed initial topography along with joints and stratigraphy

\section{RESULTS AND DISCUSSION}

A number of experimental and numerical investigation were done to investigate the effect of inclination of bedding planes to loading direction and its maximum load bearing capacity in unconfined condition. Tests like slake durability index, UCS on samples of different bedding plane inclination followed by numerical investigation of the cut slope section employing distinct element method. The results of each parameter is described below separately.

\section{A. Effect of long term weathering}

Slake durability index was conducted to understand the effect of weathering on degradation of silty shale. Rocks rich in clay show high strength when dry in comparison to the saturated conditions. The result of slake durability test shows very high slaking resulting into major disintegration after second cycle (Table II). Lee et al [15] suggests that this happens due to breaking of diagenetic bonds between the grains which destroys the capacity of the material to sustain engineering loads. Others have also suggested dissolution of cementing material in stratified rocks as the main cause of strength reduction. The low value of UCS and tensile strength clearly shows the strength degradation due to weathering. The presence of orthogonal joints promotes deeper penetration of water causing degradation and disintegration 
at sub-surface level. These phenomenon makes the interface very weak. Picarelli et al [16] further suggests that outcrops in such material is generally overlain by a veneer of soft and non-fissured clay produced by weathering and swelling which is consistent with the field observation. Moreover, the joints in the present case is inclined at $45^{\circ}$ dipping towards the slope face. The results from this analysis suggests that the rock mass will have least strength when loaded in this condition.

TABLE II RESULTS OF SLAKE DURABILITY TEST AFTER TWO CYCLES OF WETTING AND DRYING EVENT

\begin{tabular}{|l|l|l|}
\hline Samples & SDT after $^{\text {st }}$ cycle (\%) & $\begin{array}{l}\text { SDT after } \mathbf{2}^{\text {nd }} \\
\text { cycle } \\
(\%)\end{array}$ \\
\hline Fresh surface & 86 & 79 \\
\hline Failed mass & 75 & 54 \\
\hline
\end{tabular}

\section{B. Effect of inclination of bedding plane}

Several samples of silty shale were prepared with different inclination of bedding plane i.e. $0^{\circ}, 30^{\circ}, 45^{\circ}$ and $90^{\circ}$ to the direction of loading. UCS was determined for each sample to investigate the effect of inclination of bedding plane and its load carrying capacity. The data shows very informative results and clearly highlight the most vulnerable case. Bedding plane inclined at $30^{\circ}-45^{\circ}$ to the direction of loading shows least resistance to loading in unconfined condition. However, the UCS increases either below $30^{\circ}$ or above $45^{\circ}$ (Fig. 4). Similarly, several researchers in the past have performed such tests on different laminated samples on both tensile and UCS tests. Trends are almost similar and the strength is least in almost all the case in the range of $30^{\circ}-45^{\circ}$ as observed in this case.

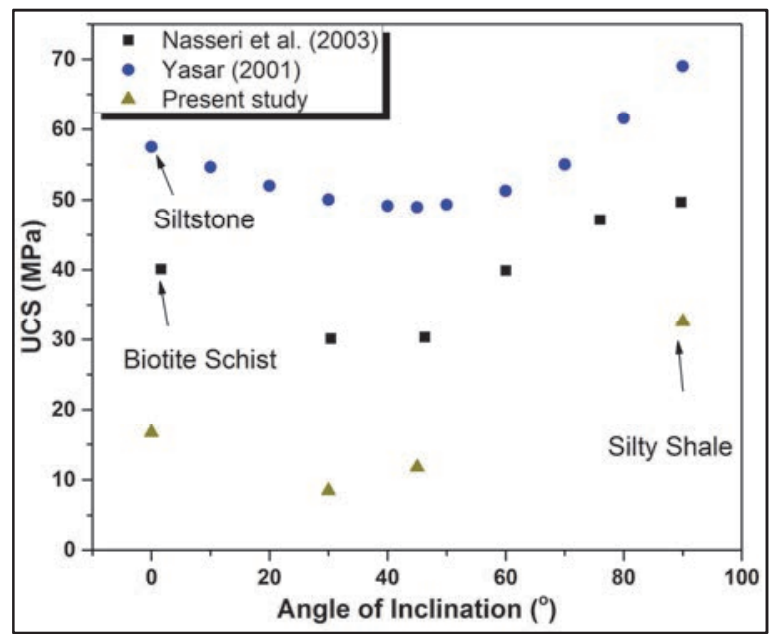

Fig. 4. Variation of compressive strength of different laminated rocks with angle to bedding plane

\section{Effect of normal load and fluid pressure on joints}

Singh et al [17], [18] observed that non-linear behaviour exists between the discharge $(Q)$ and effective fluid pressure $\left(\sigma_{\text {eff. }}\right)$ and there is a rapid decrease in $Q$ till $10 \mathrm{MPa}$ beyond which the fracture aperture closes very quickly and flow through fracture ceases (Fig. 5). Joint roughness also plays very important role in controlling the nature of fluid flow.
Fig. 5 depicts discharge behaviour of three different varieties of crystalline rocks varying in grain size. Corresponding to grain size the roughness varies in the samples which control the discharge. This a very important concept which if correlated with the conditions existing in open cut slope may provide useful ideas. The joints near the slope face up to 1-2 $\mathrm{m}$ depth are acted upon by almost zero normal stress as compared to deeper joints which tends to remain closed due to load of rock above it. Water has two significant effect on the rocks. First, it exerts extra pressure normal to fracture walls and then it degrades the joint walls which leads to significant reduction in shear strength. Therefore, open joints allow free flow of water through it and results in shallow failure.

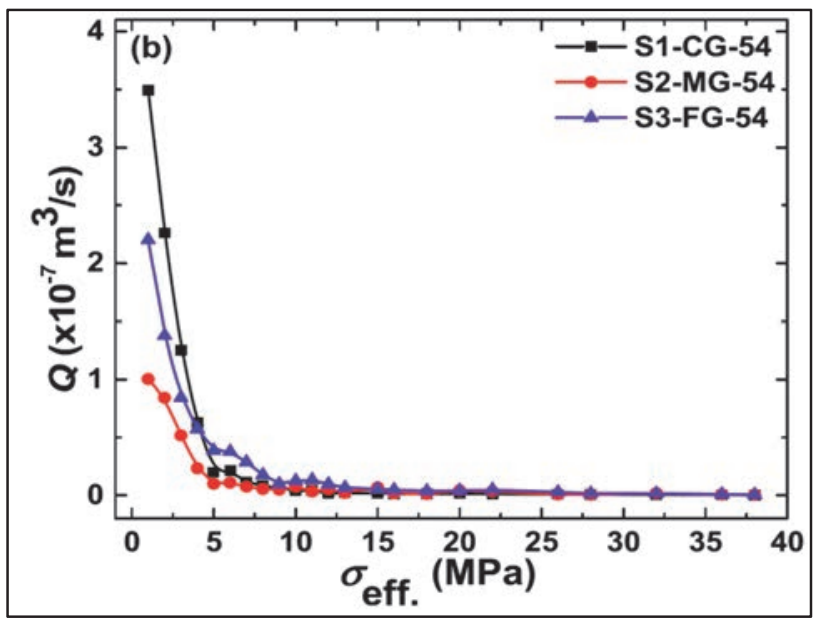

Fig. 5. Variation of discharge with effective stress for different roughness (After Singh et al. 2016))

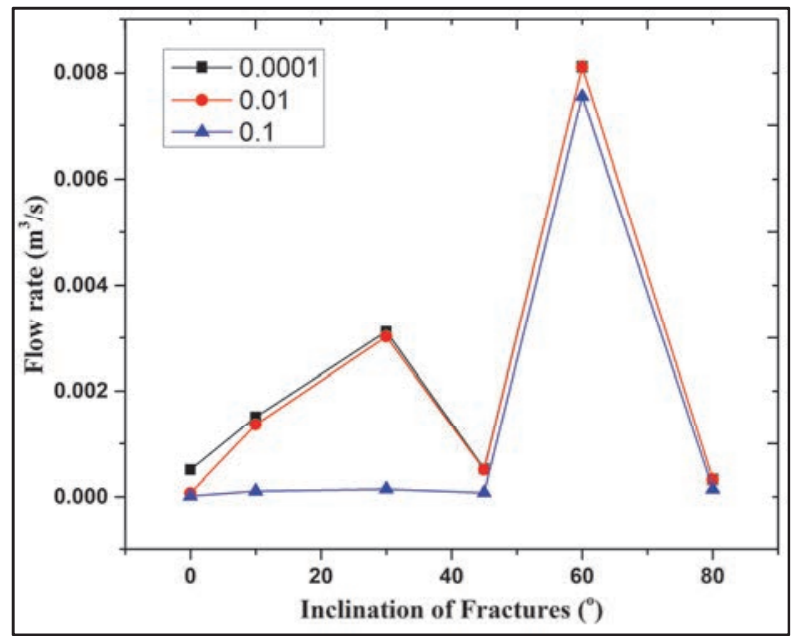

Fig. 6. Variation of flow rate for different inclination of laminations and at different normal load

\section{Effect of flow rate on inclination of fracture}

A cylindrical model of the size of core of NX size diameter $(54 \mathrm{~mm})$ was created in UDEC with different fracture inclination viz. $0^{\circ}, 10^{\circ}, 30^{\circ}, 45^{\circ}, 60^{\circ}$ and $80^{\circ}$. The base of the geometry was restrained movement in $\mathrm{x}$ and $\mathrm{y}$ direction but was allowed to move freely in other boundaries. The material properties were taken from Table I. Water was 
introduced in the model from the right boundary of the geometry for different stages and variation of flow rate was observed with different fracture inclination as well as different normal load. Three normal load was considered in this study viz. $0.0001,0.01$ and $0.1 \mathrm{MN}$. The result does not show any regular pattern, however, maximum flow rate is observed in case of fracture inclination of $60^{\circ}$ irrespective of normal load. Interestingly, the flow ceases when the normal load was increased to $0.1 \mathrm{MN}$ at around $45^{\circ}$ fracture inclination (Fig. 6).

\section{E. Deformation mechanism}

Finally, slope stability analysis was performed by employing distinct element method for gravity loading as well as coupled hydro-mechanical loading condition. The results show that during gravity loading the slope remains stable with a maximum recorded displacement of $0.07 \mathrm{~m}$ on the crest of the slope. The maximum displacement is observed by the movement of a very small block size. In the next stage, the crest of the slope was loaded with a constant stress of $1 \mathrm{MPa}$ and the displacement rises to $0.14 \mathrm{~m}$. When the same analysis was performed with the addition of water from the right boundary of the slope, the displacement increases rapidly to $1.2 \mathrm{~m}$ near the toe region of the slope (Fig. 7).

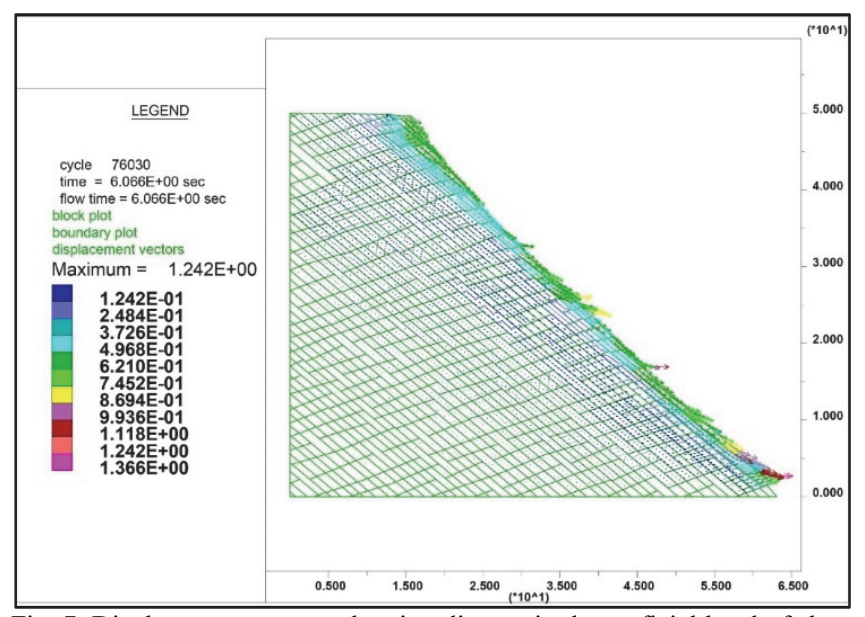

Fig. 7. Displacement vectors showing distress in the surficial level of slope face

The shift in the location of maximum displacement corresponds to the addition of water pressure within the joints. Water opens the joints near the slope face within the range of 1-2 m below the slope face. As a result, entire zone shows disturbance and the failure surface resembles a typical planar failure of very shallow depth. Kinematically, the daylighting joints are the most critical and are inclined at $45^{\circ}$ to the slope face. This architecture of joints also confirms to a typical planar failure. The depth of failure completely depends upon the orthogonal join sets and the ability of water to degrade and disintegrate the sub-surface rocks. Clay rich rocks show high rate of weathering along with significant swelling and shrinkage. At a particular time when fluid reaches the slope face, entire slope face starts showing continuous movement. This increase in hydraulic conductivity and reduction in shear strength exerts tremendous pressure on the blocks enabling complete detachment. Correlation of results from fig. 4,5 and 6 to that of fig. 7 shows that the present condition of joints $\left(45^{\circ}\right)$ are arranged in such a way that they assume least strength when loaded. The combined effect of weathering, reduced shear strength, fluid pressure, kinematic arrangement of joints leads to slope failure in an unplanned civil engineering structure. Moreover, when the persistent joints are adversely oriented to slope face, there is minimum deformation in rock mass and progressive failure initiates by slippage along the joint by a process where shear strength continuously decreases from peak to residual values [19].

\section{CONCLUSIONS}

A cut slope section excavated in stratified rock mass was analysed to investigate the effective loading direction, maximum allowed load on the crest of the slope, zones of maximum displacement and maximum flow rate observed along the slope face, mode and depth of failure plane. The results were obtained by a combination of experimental and numerical analysis. Some concluding remarks are as follows:

- A number of unplanned settlement was observed above the crest of the slope as well as over the slope face. Three joint sets are present and the most critical is the persistent bedding plane parallel joint followed by the orthogonal joints.

- Heavy precipitation in monsoonal months and improper drainage galleries allow water to seep into the slope through orthogonal joint sets enabling permeation of water to sub-surficial levels. These joints are also responsible for kinematic release of the blocks.

- Ability of clay rich rocks to retain water within its pore spaces leads to significant weathering and degradation and disintegration of rocks at deeper levels. This also reduces the shear strength continuously from peak to residual values.

- A significant strength reduction parallel and perpendicular to bedding plane leads to decrease in load bearing capacity of the rocks. The minimum strength was observed for bedding plane inclined at $30^{\circ}-45^{\circ}$ and maximum at $0^{\circ}$.

- Slake durability test intended to assess the durability of rocks against external weathering agents like water and elevated temperatures was done for two cycles. The results show significant slaking and disintegration of rocks following second cycle. The low value of UCS also confirms to the extreme weathering in the exposed cut slopes.

- The results of numerical simulation show that the slope is stable during only gravity loading condition. When a constant load of $1 \mathrm{MPa}$ was applied on the crest of the slope the maximum displacement shoots up to $0.14 \mathrm{~m}$. when the same case was modelled under coupled hydromechanical loading, the displacement increases to $1.2 \mathrm{~m}$. The location of maximum displacement shifts from crest to mid portion to the toe of the slope, respectively. The continuous increase in hydraulic conductivity near the slope face leads to block detachment and hence, slope failure. 


\section{REFERENCES}

[1] H. Tang, R. Yong, and M. A. M. Ez Eldin, "Stability analysis of stratified rock slopes with spatially variable strength parameters: the case of Qianjiangping landslide," Bull. Eng. Geol. Environ., 2016.

[2] M. Gencer, "Progressive Failure in Stratified and Jointed Rock Mass," Rock Mech. Rock Eng., vol. 18, pp. 267-292, 1985.

[3] J. J. Dong, C. H. Tu, W. R. Lee, and Y. J. Jheng, "Effects of hydraulic conductivity/strength anisotropy on the stability of stratified, poorly cemented rock slopes," Comput. Geotech., vol. 40, pp. 147-159, 2012.

[4] A. W. Bishop and L. Bjerrum, "The relevance of the triaxial test to the solution of stability problems," in Research Conference on Shear Strength of Cohesive Soils, 1960, no. 118 I, pp. 437-501.

[5] P. R. Vaughan and H. J. Walbancke, "Pore pressure changes and the delayed failure of cutting slopes in overconsolidated clay," Géotechnique, vol. 23, no. 4, pp. 531-539, 1973.

[6] L. Bjerrum, "Progressive failure in slopes of overconsolidated plastic clay and clay shales," J. Soil Mech. Found. Div, vol. 93, no. SM5, pp. 1-49, 1967.

[7] S. Yagiz, "Overview of Classification and Engineering Properties of Shales for Design Considerations," Constr. Mater. Issues, pp. 156-165, 2001.

[8] F. Donath, "Experimental study of shear failure in anisotropic rocks," Geol. Soc. Am. Bull., vol. 72, no. June, pp. 985-990, 1961.

[9] F. G. Bell, J. C. Cripps, and M. G. Culshaw, "A review of the engineering behaviour of soils and rocks with respect to groundwater," Geol. Soc. London, Eng. Geol. Spec. Publ., vol. 3, no. 1, pp. 1-23, 1986.

[10] A. Kainthola, P. K. Singh, A. B. Wasnik, and T. N. Singh, "Distinct Element Modelling of Mahabaleshwar Road Cut Hill Slope," Geomaterials, vol. 2, no. 4, pp. 105-113, 2012.

[11] A. Kainthola, P. K. Singh, and T. N. Singh, "Stability investigation of road cut slope in basaltic rockmass, Mahabaleshwar, India," Geosci. Front., vol. 6, no. 6, pp. 837-845, 2015.

[12] L. Jing and O. Stephansson, Fundamentals of discrete element methods for rock engineering : theory and applications. Elsevier, 2007.

[13] P. A. Cundall and R. D. Hart, "Numerical Modelling of Discontinua," Eng. Comput., vol. 9, no. 2, pp. 101-113, 1992.

[14] P. A. Witherspoon, J. S. Y. Wang, K. Iwai, and J. E. Gale, "Validity of Cubic Law for fluid flow in a deformable rock fracture," Water Resour. Res., vol. 16, no. 6, pp. 1016-1024, 1980.

[15] D. H. Lee, Y. E. Yang, and H. M. Lin, “Assessing slope protection methods for weak rock slopes in Southwestern Taiwan," Eng. Geol., vol. 91, no. 2-4, pp. 100-116, 2007.

[16] L. Picarelli, G. Urciuoli, A. Mandolini, and M. Ramondini, "Softening and instability of natural slopes in highly fissured plastic clay shales," Nat. Hazards Earth Syst. Sci., vol. 6, no. 4, pp. 529-539, 2006.

[17] K. K. Singh, D. N. Singh, and R. P. Gamage, "Effect of sample size on the fluid flow through a single fractured granitoid," J. Rock Mech. Geotech. Eng., vol. 8, no. 3, pp. 329-340, 2016.

[18] K. K. Singh, D. N. Singh, and P. G. Ranjith, "Laboratory Simulation of Flow through Single Fractured Granite," Rock Mech. Rock Eng., vol. 48, pp. 987-1000, 2015.

[19] E. Eberhardt, D. Stead, and J. S. Coggan, "Numerical analysis of initiation and progressive failure in natural rock slopes - the 1991 Randa rockslide," Int. J. Rock Mech. Min. Sci., vol. 41, no. 1, pp. 69-87, Jan. 2004. 